\title{
Development and application of a statistical constitutive model of damaged rock affected by the load-bearing capacity of damaged elements"
}

\author{
Ting-chun $\mathrm{LI}^{\dagger}$, Lian-xun LYU, Shi-lin ZHANG, Jie-cheng SUN \\ (Shandong Provincial Key Laboratory of Civil Engineering Disaster Prevention and Mitigation, \\ Shandong University of Science and Technology, Qingdao 266590, China) \\ †E-mail: tchli_sd@163.com
}

Received Feb. 10, 2015; Revision accepted July 1, 2015; Crosschecked July 9, 2015

\begin{abstract}
It is difficult to establish a constitutive model of damage for rock materials due to the complex meso-mechanism of the rock deterioration process. In this paper, by analysis of the damage mechanism, the reason for the existence of a rock damage threshold is explained and we conclude that damaged rock elements of micro scale can still bear stress. The correlation between damaged and undamaged elements is examined in relation to stress distribution. Rocks under different initial conditions can be defined as undamaged materials with different properties, to avoid the issue of the solution of the undamaged condition and to simplify the damage model. On the basis of the Mohr-Coulomb criterion and theories of continuum damage and statistical mechanics, a constitutive model of rock materials affected by the load-bearing capacity of damaged elements under triaxial compression is established. Compared with previous experimental data and theoretical results, we show that this model can reflect the stress-strain relationship of the whole process of rock failure. In particular, the description of the strain softening stage after peak strength is proved to be more reasonable. Programming of the constitutive model applied to stability analysis of the Qingdao subway station is achieved by secondary development of FLAC ${ }^{3 \mathrm{D}}$. The computing results compare very well with field monitoring data, indicating that the constitutive model of damaged rock can reflect the deterioration effect of weathered rock at the site. This constitutive model of rock damage may provide a useful reference for practical application.
\end{abstract}

Key words: Rock materials, Damaged elements, Statistical theory, Load-bearing capacity, Constitutive model doi:10.1631/jzus.A1500034

Document code: A

CLC number: TU45

\section{Introduction}

Rock material is one of the most common natural materials in civil engineering. The physical and mechanical properties of rock have attracted much attention in engineering research (Andrä et al.,

\footnotetext{
* Project supported by the National Natural Science Foundation of China (Nos. 51279096 and 51409154), the Natural Science Foundation of Shandong Province (No. ZR2012EEM030), and the Technology Innovation Foundation of Shandong University of Science and Technology (No. YC140207), China (iD) ORCID: Ting-chun LI, http://orcid.org/0000-0002-1275-0517; Lianxun LYU, http://orcid.org/0000-0002-6066-5149

(c) Zhejiang University and Springer-Verlag Berlin Heidelberg 2015
}

2013; Shan and Di, 2013). The key issues for rock mechanics research include the initiation and propagation of microdefects affected by the environment and external loading, the dynamics of damage and the evolution process of damaged materials, and the stress-strain constitutive relationship (Molladavoodi and Mortazavi, 2011; Mortazavi and Molladavoodi, 2012; Chandler, 2013; Levasseur et al., 2013).

The key challenges in rock damage research lie in the constitutive theory and evolution equations of damaged rock. Three approaches have commonly been used in mechanical damage research: phenomenological theory, meso-damage constitutive theory, and constitutive theory that considers the nonlocal 
effects based on statistics. The phenomenological model focuses on the macro-behavior of a rock mass, while the meso-damage constitutive model is readily applied to describe the physical and mechanical features of the damage process (Kaiser and Morgenstern, 1981; Yu and Feng, 1997; Ladani and Dasgupta, 2009; Chen, 2014). The macro results and mesoscopic mechanisms of different materials and damage processes are so complicated that it is difficult to describe fully the mechanics of the affected mechanisms based on the mechanic model. However, in terms of statistical and stochastic damage theory, much has been achieved with the knowledge of the process and rules for damage evolution ( $\mathrm{Yu}$ and Feng, 1997).

Statistical damage theory, first proposed by Krajcinovic and Silva (1982), shows that the internal defects of rock materials are distributed randomly. Some researchers (Lee and Simunovic, 2001; Cao et al., 2007; Rinaldi and Lai, 2007; Jiang et al., 2010; Deng and Gu, 2011; Zhang et al., 2013) who further developed the above theory, assumed the randomness of the strength of rock elements as different function distributions, such as the Weibull and Gaussian distributions. Based on the spatially mobilized plane, Drucker-Prager, Mohr-Coulomb, and Hoek-Brown criteria, they made use of the strain equivalence hypothesis put forward by Lemaitre (1984) to deduce the constitutive equation for the process of dynamic rock damage. However, the strain equivalence hypothesis based on the traditional view, which considers that micro scale damaged elements cannot bear stress, does not comply with reality. Therefore, it is difficult to use the constitutive equation based on that hypothesis to reflect the strain-softening behaviors after material yielding. To overcome the defects of traditional damage theories (Lemaitre, 1984; Li et al., 2012; Fu et al., 2013; Xu et al., 2013), the correction coefficient of residual strength was introduced by some researchers (Li et al., 2007; Shi et al., 2011; Wang et al., 2013) to modify the constitutive relation of rock materials and to establish a statistical constitutive model of damage which can reflect the influence of specific confining pressure. Taking the effect of residual strength into consideration, the model is relatively reasonable but fails to analyze the ability of damaged elements to bear stress.
Thus, the constitutive model of rock materials established on the basis of statistical damage theory still needs to be improved. In this paper, we discuss the stress distribution relationship between damaged and undamaged elements from the perspective of the rock damage mechanism. Based on the continuum of damage and statistical theories, a constitutive model of rock materials affected by the load-bearing capacity of damaged elements and under triaxial compression is deduced. Compared with previous experimental data and theoretical results, the constitutive model is proved to be reasonable and has been applied in engineering practice.

\section{Rock damage mechanism}

Regarding the external environment, rock materials suffer from the repeated action of loadingunloading, which inevitably leads to initial micro imperfections. To investigate the damage and deterioration mechanism of rock under the effect of initial defects, it is assumed that there is a certain initial defect element (microcrack). A model of a rock specimen with an initial defect element can be established (Fig. 1). Undamaged elements in rock can be simulated by using isotropic homogeneous material.

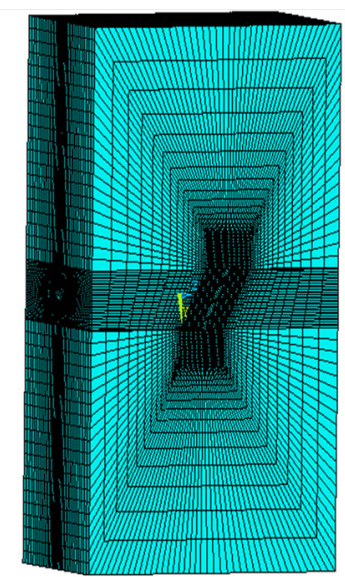

Fig. 1 Calculation model of a rock specimen

The dimensions of the rock specimen model were $50 \mathrm{~mm} \times 100 \mathrm{~mm} \times 40 \mathrm{~mm}$. The Mohr-Coulomb constitutive model was adopted, with a total of 266350 units and 279262 nodes. The model simulated the initial defect element as a penny-shaped 
crack with a radius of $10 \mathrm{~mm}$ and thickness of $0.5 \mathrm{~mm}$ in the middle of the model.

A load from different directions was applied to the model of rock specimen to simulate triaxial compression. The state of stress distribution around the microcrack was obtained (Fig. 2). The model shows that the stress state around the microcrack tip is very complex and there is obvious stress concentration. With increasing deformation and stress, rock elements near the microcrack are in the most disadvantaged stress state. Crack propagation or degradation of material properties necessarily starts from the area near the damaged elements. Eventually, all rock elements are converted into damage elements, and the specimen is completely destroyed.

(a)

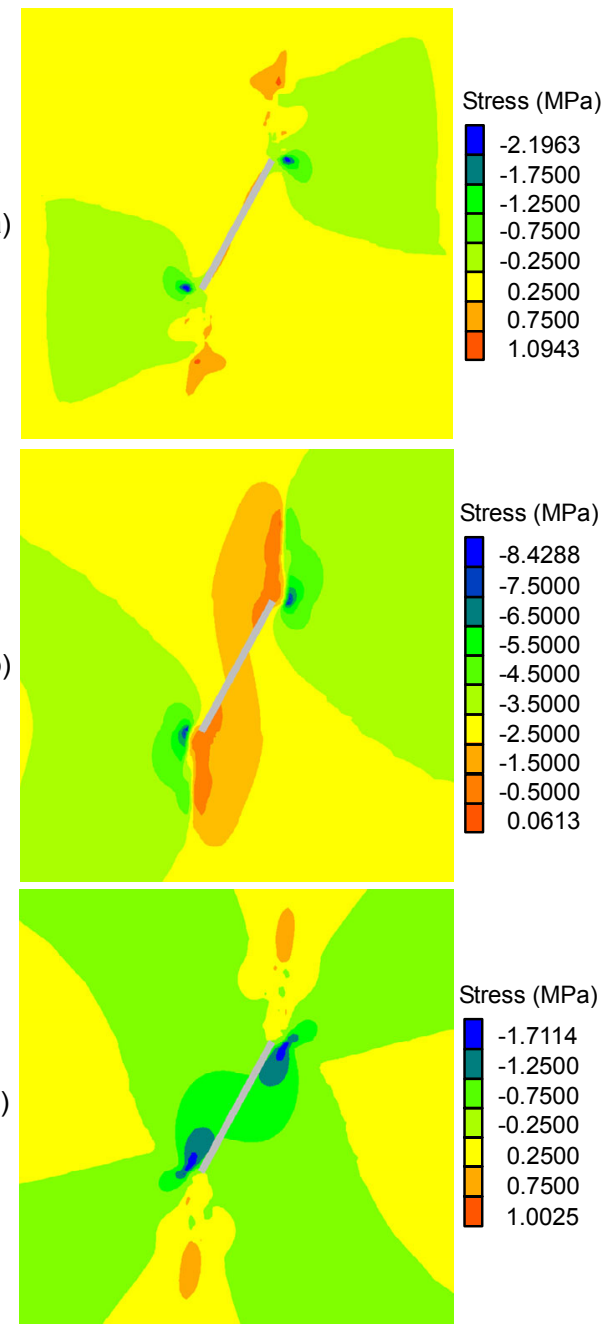

Fig. 2 Stress distribution around the microcrack after completion of calculation: (a) distribution of maximum principal stress; (b) distribution of minimum principal stress; (c) distribution of shear stress
Fig. 3 shows the complete stress-strain curve of strongly weathered granite under uniaxial compression. The curve is divided into five stages and shows the deformation characteristics and damage mechanism of each stage from a microscopic viewpoint. The $O A$ segment is defined as the fracture compaction stage, where the initial damaged elements become gradually enclosed, leading to the compaction of the rock. The $A B$ segment is known as the linear elasticity stage, where the stress concentration area occurs near the microcracks. The specimen is still in the initial damaged condition since the stress value is lower than the strength of the rock elements. The $B C$ segment is the stable expansion stage, where the specimen begins to deteriorate since the stress near the microcracks exceeds the strength of the rock elements. But the number of damaged elements is small and the yielding is inconspicuous. The $C D$ segment represents an unstable expansion stage, where the rock turns into a yielding state with the number of damaged elements increasing and the speed of specimen deterioration accelerating. The $D E$ segment covers the break stage, where the rock elements are severely damaged, causing the development and connection of microcracks and micro holes. Finally, the specimen is totally destroyed. The point $E$ is defined as the residual strength of the materials.

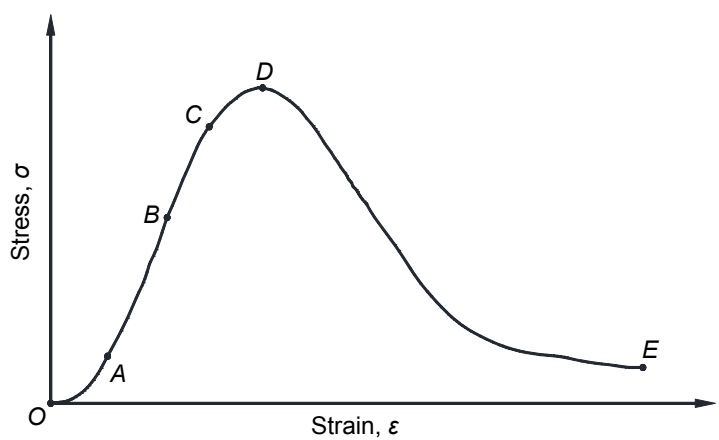

Fig. 3 Stress-strain curve of strongly weathered granite

The above analysis shows that deformation submitting to linear elasticity explains the effect of the threshold in the damage process of rock materials (Cao et al., 2007; 2008). The stress near the damaged elements does not match the strength of the microelements when the stress and strain are at a lower level. Furthermore, in view of the deformation 
curve of rock and the characteristic of material residual strength, the damaged elements have a certain stress bearing capacity.

\section{Establishment of a rock damage model}

\subsection{Damage variable}

Symbolizing the state variable of the extent of rock failure, a damage variable can be defined by statistical theory as follows (Wang et al., 2007; Cao et al., 2008):

$$
D=N_{\mathrm{f}} / N
$$

where $N_{\mathrm{f}}$ is the number of damaged elements in a damaged state, and $N$ is the total number of damaged and undamaged elements.

From the perspective of the acting surface of force, Eq. (1) could be converted into:

$$
D=\frac{N_{\mathrm{f}}}{N}=\frac{A_{\mathrm{f}}}{A},
$$

where $A_{\mathrm{f}}$ is the action area of the damaged elements in a damaged state, and $A$ is the total action area of damaged and undamaged elements.

\subsection{Damage model}

To simplify the calculation, traditional theories (Lemaitre, 1984; Li et al., 2012; Fu et al., 2013; Xu et al., 2013) assume that micro-scale damaged elements in materials cannot bear stress once they are formed. However, the bearing capacity of damaged elements cannot be ignored because macroscopical deformation has a close relationship with mesodamage, and studies of statistical constitutive damage models must focus on the mesoscopic level.

The damage to the rock elements can be defined as the result of reduced stiffness caused by the change in the physical properties of undamaged elements. The stress of damaged and undamaged elements under external load distributes according to the value of stiffness, and $\eta$ is defined as the correction coefficient of damage.

Assume that the total stress of rock materials is $\sigma$, the stress borne by undamaged parts is $\sigma_{\mathrm{w}}$, and the stress borne by damaged parts is $\sigma_{\mathrm{f}}$. Based on the rock damage mechanism, a damage model of rock materials in various states can be established.

(1) Undamaged condition:

$$
\sigma_{\mathrm{w}}=\sigma, \quad \sigma_{\mathrm{f}}=0 .
$$

(2) Initial damage condition:

$$
\sigma A=\sigma_{\mathrm{w} 0}\left(A-A_{\mathrm{f}}\right)+\sigma_{\mathrm{f}} A_{\mathrm{f}},
$$

where $\sigma_{\mathrm{w} 0}$ is the effective stress of the initial damage condition.

Divide Eq. (4) by $A$ on its left and right sides:

$$
\sigma=\sigma_{\mathrm{w} 0}\left(1-D_{0}\right)+\sigma_{\mathrm{f}} D_{0}
$$

where $D_{0}$ is the initial damage variable of rock materials.

From the stress distribution relationship between damaged and undamaged elements, we conclude that:

$$
\sigma_{\mathrm{f}}=\eta \sigma_{\mathrm{w}}
$$

Substituting Eq. (6) into Eq. (5) gives:

$$
\sigma=\sigma_{\mathrm{w} 0}\left(1-D_{0}+\eta D_{0}\right)
$$

(3) Random damage condition:

Similar to the initial damage condition, the formula can be simplified as

$$
\sigma=\sigma_{\mathrm{w}}(1-D+\eta D)
$$

(4) Completely damaged condition:

$$
\sigma_{\mathrm{f}}=\sigma, \quad \sigma_{\mathrm{w}}=0
$$

The stress-strain curve of the undamaged elements in the rock deformation process can be drawn according to the above damage model (Fig. 4). The curve is similar to that of the model of Mazars and Cabot (1989), but its intended meaning is quite different. In the curve, the $O A$ segment represents the initial damage condition where the rock specimen is in the linear elastic deformation stage before the stress matches the element strength. The $A B$ segment 
represents the random damage condition, where the stress of undamaged parts increases rapidly along with deterioration of material properties. The point $C$ shows the complete damaged condition, where the total stress is borne entirely by the damaged elements.

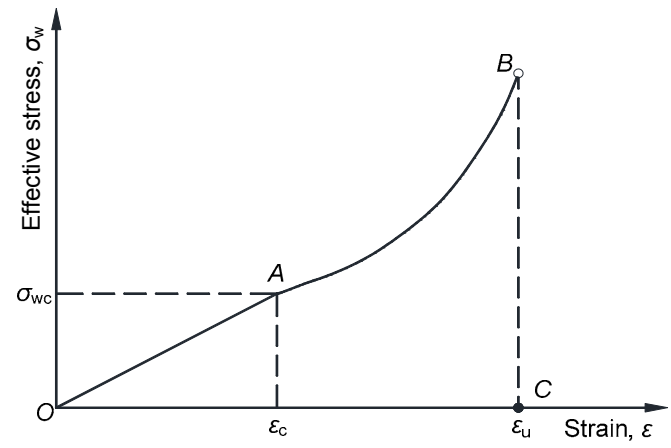

Fig. 4 Stress-strain curve of undamaged elements in the process of rock deformation

$\sigma_{\mathrm{wc}}$ is the maximum effective stress of the initial damage condition; $\varepsilon_{\mathrm{c}}$ is the corresponding strain under the maximum effective stress; $\varepsilon_{\mathrm{u}}$ is the maximum strain of the rock deformation process

\subsection{Simplification of the damage model}

Stress concentrated near initial defects is the main cause of deterioration in the rock material, while the initial damage variable is too small to be calculated. Assuming that the initial damage condition equals that of the undamaged condition for materials, namely, the initial damage variable of rock $D_{0}=0$, then the solution of the initial damage variable can be avoided by taking rock of different initial conditions as materials of different properties. The above models can be simplified as

$$
\sigma_{\mathrm{w} 0}=\sigma, \quad \sigma_{\mathrm{w}}=\frac{1}{1-D+\eta D} \sigma .
$$

The damage variable undergoes fewer changes in the stable expansion stage of the rock, and the stress-strain curve still approximates a straight line. The physical and mechanical properties before the state of rock yield change very little, so the material degradation is not obvious. Therefore, the yield point of the rock should be the starting point of damage evolution. That is, the damage variable before rock yield should permanently be zero.

\section{Statistical constitutive model of damage}

\subsection{Establishment of damage evolution equation}

A statistical damage evolution equation can be established using methods put forward by Cao et al. (2008). Assuming that the strength of the rock elements $F$ complies with the Weibull distribution, then the distribution of the density function can be expressed as

$$
P(F)=\frac{m}{F_{0}}\left(\frac{F}{F_{0}}\right)^{m-1} \exp \left[-\left(\frac{F}{F_{0}}\right)^{m}\right]
$$

where $m$ and $F_{0}$ are parameters related to mechanical properties of rock materials.

Given the randomness of damage to rock elements, the evolution equation of damage variable $D$ can be expressed as

$$
D=\int_{0}^{F} P(x) \mathrm{d} x=1-\exp \left[-\left(\frac{F}{F_{0}}\right)^{m}\right] .
$$

The Mohr-Coulomb yield criterion can be taken as the strength criterion for rock materials:

$$
\frac{1}{2}\left(\sigma_{\mathrm{w} 1}-\sigma_{\mathrm{w} 3}\right)-\frac{1}{2}\left(\sigma_{\mathrm{w} 1}+\sigma_{\mathrm{w} 3}\right) \sin \varphi_{\mathrm{f}}=c_{\mathrm{f}} \cos \varphi_{\mathrm{f}},
$$

where the subscript number $i(i=1,2,3)$ refers to the direction of the axis, $c_{\mathrm{f}}$ is the cohesion when rock is damaged, and $\varphi_{\mathrm{f}}$ is the internal friction angle.

Assuming that the starting point of damage evolution is the yield point of rock, set

$$
\begin{gathered}
F=f\left(\sigma_{\mathrm{w}}\right)=\left(\sigma_{\mathrm{w} 1}-\sigma_{\mathrm{w} 3}\right)-\left(\sigma_{\mathrm{w} 1}+\sigma_{\mathrm{w} 3}\right) \sin \varphi_{\mathrm{y}}-k_{0}, \\
k_{0}=2 c_{\mathrm{y}} \cos \varphi_{\mathrm{y}}
\end{gathered}
$$

where $c_{\mathrm{y}}$ is the cohesion when the rock has yielded, and $\varphi_{\mathrm{y}}$ is the internal friction angle.

According to the generalized Hooke's law,

$$
\varepsilon_{i}=\frac{1}{E}\left[(1+v) \sigma_{\mathrm{w} i}-v\left(\sigma_{\mathrm{w} 1}+\sigma_{\mathrm{w} 2}+\sigma_{\mathrm{w} 3}\right)\right]
$$

where $E$ is the elasticity modulus, and $v$ is the Poisson's ratio. Substituting Eq. (10) into Eq. (16), we can obtain 


$$
1-D+\eta D=\frac{1}{E \varepsilon_{i}}\left[(1+v) \sigma_{i}-v\left(\sigma_{1}+\sigma_{2}+\sigma_{3}\right)\right] .
$$

Under triaxial compression, Eq. (17) can be simplified as

$$
1-D+\eta D=\frac{1}{E \varepsilon_{1}}\left[\sigma_{1}-v\left(\sigma_{2}+\sigma_{3}\right)\right] .
$$

Substituting Eq. (18) into Eq. (10), we can obtain

$$
\sigma_{\mathrm{w} i}=\frac{E \varepsilon_{1} \sigma_{i}}{\sigma_{1}-v\left(\sigma_{2}+\sigma_{3}\right)} .
$$

Substituting Eq. (19) into Eq. (14), the value of the strength of the rock elements $F$ can be defined as

$$
F=\frac{\left(\sigma_{1}-\sigma_{3}\right) E \varepsilon_{1}-\left(\sigma_{1}+\sigma_{3}\right) E \varepsilon_{1} \sin \varphi_{y}}{\sigma_{1}-v\left(\sigma_{2}+\sigma_{3}\right)}-k_{0} .
$$

Substituting Eq. (20) into Eq. (12) and taking the effect of the damage threshold into account, the statistical damage evolution model can be described as

$$
D= \begin{cases}1-\exp \left[-\left(\frac{F}{F_{0}}\right)^{m}\right], & F \geq 0, \\ 0, & F<0 .\end{cases}
$$

\subsection{Establishment of a constitutive model of damage}

The constitutive equation of damage under triaxial compression can be obtained from Eq. (18):

$$
\sigma_{1}=E \varepsilon_{1}(1-D+\eta D)+v\left(\sigma_{2}+\sigma_{3}\right) .
$$

Substituting Eq. (21) into Eq. (22), the statistical constitutive model of damage in the whole process of rock deformation can be described as

$$
\sigma_{1}= \begin{cases}E \varepsilon_{1}(1-D+\eta D)+v\left(\sigma_{2}+\sigma_{3}\right), & F \geq 0, \\ E \varepsilon_{1}+v\left(\sigma_{2}+\sigma_{3}\right), & F<0 .\end{cases}
$$

\subsection{Determination of parameters}

Based on the triaxial compression test curve, an approximate fitting correction coefficient of damage $\eta$ can be obtained. The specific method is as follows.

When a rock specimen is completely damaged, then $D=1$, and from Eq. (22), we can obtain

$$
\sigma_{\mathrm{r}}=\eta E \varepsilon_{\mathrm{r}}+v\left(\sigma_{2}+\sigma_{3}\right),
$$

where $\sigma_{\mathrm{r}}$ is the residual strength, and $\varepsilon_{\mathrm{r}}$ is the residual strain of the rock.

Therefore, the correction coefficient of damage $\eta$ can be expressed as follows:

$$
\eta=\frac{\sigma_{\mathrm{r}}-v\left(\sigma_{2}+\sigma_{3}\right)}{E \varepsilon_{\mathrm{r}}} .
$$

The theory of extreme value can be adopted to determine the values of $m$ and $F_{0}$, which are parameters of the Weibull distribution, and then from Eq. (22), we can obtain

$$
\left.\frac{\mathrm{d} \sigma_{1}}{\mathrm{~d} \varepsilon_{1}}\right|_{\sigma_{1}=\sigma_{\mathrm{p}}, \varepsilon_{1}=\varepsilon_{\mathrm{p}}}=0,
$$

where $\sigma_{\mathrm{p}}$ is the peak intensity of rock, and $\varepsilon_{\mathrm{p}}$ is the corresponding strain under peak intensity.

The stress-strain relationship of the deformation curve peak point can be concluded from Eq. (22):

$$
\sigma_{\mathrm{p}}=E \varepsilon_{\mathrm{p}}\left(1-D_{\mathrm{p}}+\eta D_{\mathrm{p}}\right)+v\left(\sigma_{2}+\sigma_{3}\right),
$$

where $D_{\mathrm{p}}$ is the corresponding damage variable under the peak intensity.

Combining Eqs. (26) and (27), $m$ and $F_{0}$ can be expressed as

$$
\begin{gathered}
m=-\frac{[\eta+(1-\eta) B] A F_{\mathrm{p}}}{(1-\eta) B \ln B}, \\
F_{0}=F_{\mathrm{p}} /(-\ln B)^{1 / m},
\end{gathered}
$$

where

$$
\begin{gathered}
A=\frac{\sigma_{\mathrm{p}}-v\left(\sigma_{2}+\sigma_{3}\right)}{\left[\sigma_{\mathrm{p}}-\sigma_{3}-\left(\sigma_{\mathrm{p}}+\sigma_{3}\right) \sin \varphi_{\mathrm{y}}\right] E \varepsilon_{\mathrm{p}}}, \\
B=\frac{\sigma_{\mathrm{p}}-v\left(\sigma_{2}+\sigma_{3}\right)-\eta E \varepsilon_{\mathrm{p}}}{(1-\eta) E \varepsilon_{\mathrm{p}}} \\
F_{\mathrm{p}}=\frac{\left(\sigma_{\mathrm{p}}-\sigma_{3}\right) E \varepsilon_{\mathrm{p}}-\left(\sigma_{\mathrm{p}}+\sigma_{3}\right) E \varepsilon_{\mathrm{p}} \sin \varphi_{\mathrm{y}}}{\sigma_{\mathrm{p}}-v\left(\sigma_{2}+\sigma_{3}\right)}-k_{0} .
\end{gathered}
$$




\section{Verification and analysis of the model}

In this study, data processing was conducted based on the test data of Kawamoto et al. (1988) to determine the model parameters and make theoretical curves. The rationality of the constitutive model was verified by comparison with the theoretical curves of Cao et al. (2008). As can be seen from the test data, the elasticity modulus of rock $E=51.62 \mathrm{GPa}$, Poisson's ratio $v=0.25$, internal friction angle in yield state $\varphi_{\mathrm{y}}=40.24^{\circ}$, yield cohesion $c_{\mathrm{y}}=24.80 \mathrm{MPa}$, internal friction angle in the damage state $\varphi_{\mathrm{f}}=44.01^{\circ}$, and the damage cohesion $c_{\mathrm{f}}=27.96 \mathrm{MPa}$.

\subsection{Verification of the constitutive model of damage}

Fig. 5 shows a comparison of the present model under specific confining pressure with test curves from Kawamoto et al. (1988) and theoretical curves of Cao et al. (2008). The theoretical curves in this paper and those of Cao et al. (2008) are both consistent with the test data, and they reflect the stressstrain relationship of rock under different confining pressures. Both kinds of constitutive models consider the influence of the damage threshold, and in both models the starting points of damage are chosen as the yield point. Therefore, their theoretical curves before the rock yields coincide completely, which reflects the linear elastic deformation characteristics before rock damage. After the stage of yielding, considering the fact that damaged elements can bear stress, our theoretical curves more truly reflect the strain softening properties of rocks compared with those of Cao et al. (2008).

Fig. 6 reflects the effect of different confining pressures on theoretical curves. As confining pressure increases, the damage starting point (yield point) moves backwards gradually. The rock strength increases significantly and the rock shows a tendency to develop from strain softening to hardened. Consequently, the constitutive model in this study can reasonably reflect the physical and mechanical properties of rock materials, since the results are in accordance with the actual conditions.

\subsection{Analysis of the damage evolution model}

Fig. 7 shows the test curves and theoretical curves where damage variable $D$ changes with $\sigma_{1}$
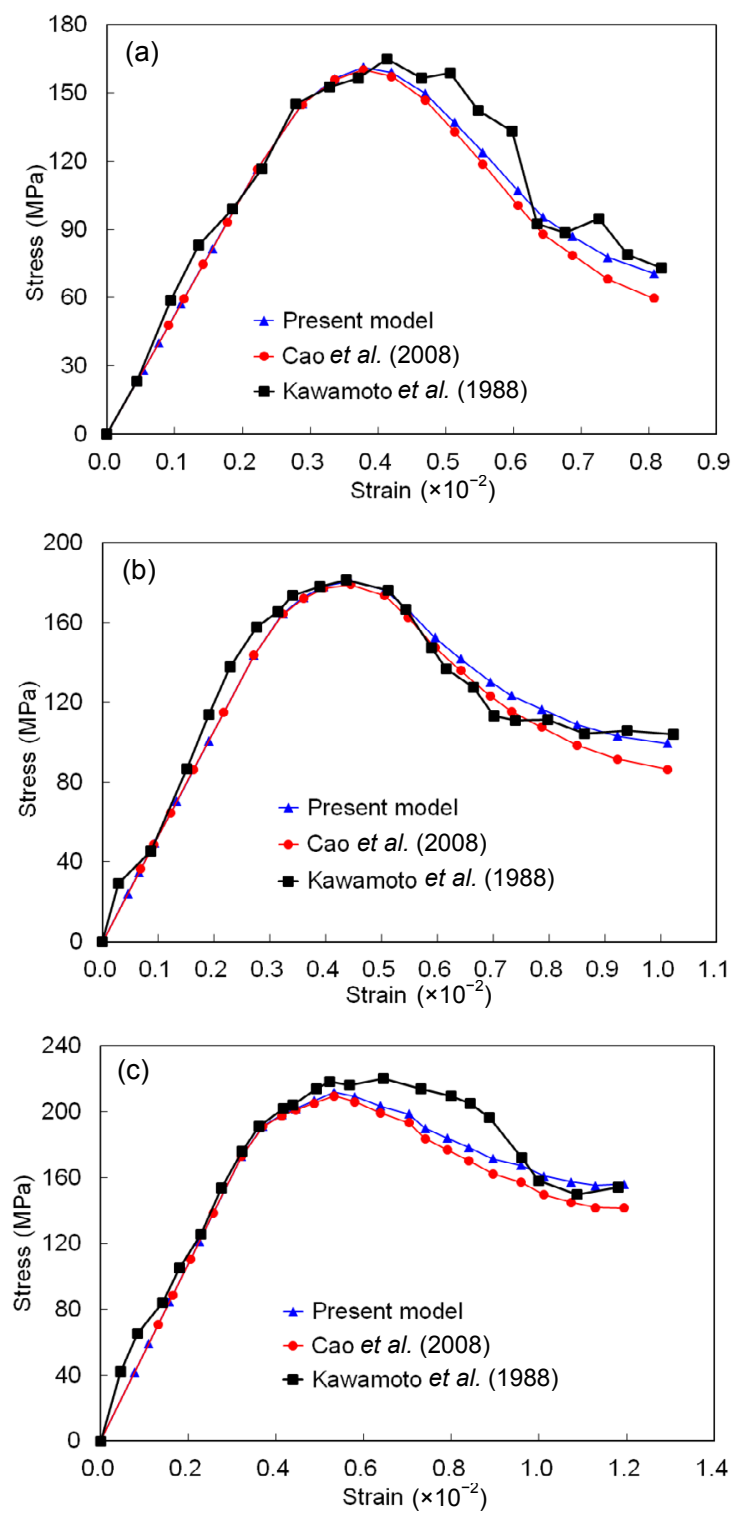

Fig. 5 Comparison of present model under specific confining pressure with test curves of Kawamoto et al. (1988) and theoretical curves of Cao et al. (2008)

(a) Confining pressure $\sigma_{2}=\sigma_{3}=3.5 \mathrm{MPa}$; (b) $\sigma_{2}=\sigma_{3}=7.0 \mathrm{MPa}$; (c) $\sigma_{2}=\sigma_{3}=14.0 \mathrm{MPa}$

under different confining pressures. Fig. 8 shows the test curves and theoretical curves where damage variable $D$ changes with $\varepsilon_{1}$ under different confining pressures.

When the stress and strain levels are low, the damage variable of rock is irregular, even negative, due to the effect of pore compaction and the damage threshold (Figs. 7a and 8a). This does not agree with the actual situation. The damage variable should be a constant value on the condition that the rock 
elements are intact with low stress and strain values and material deformation matches the characteristics of linear elasticity.

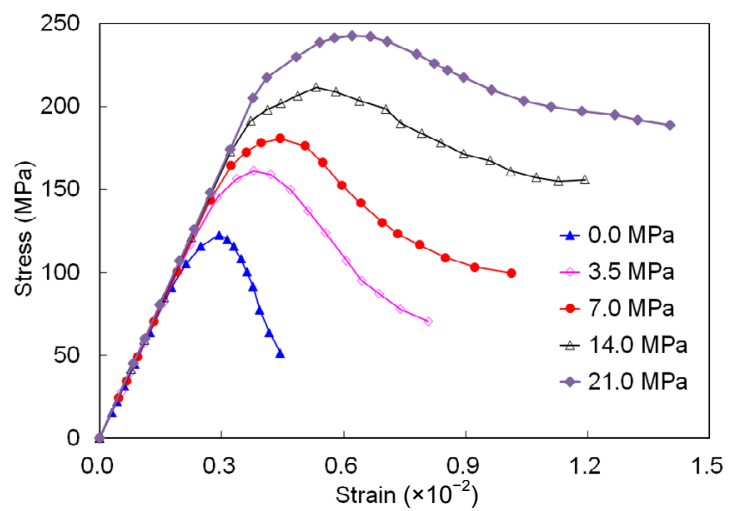

Fig. 6 Effect of different confining pressures on stressstrain curves

Fig. $7 \mathrm{~b}$ and Fig. $8 \mathrm{~b}$ express the theoretical trend of damage evolution where rock materials change with stress, strain, and confining pressure. In this study, the damage evolution model not only reflects the linear elastic deformation characteristic before rock yield, but also expresses the reasonable development rule where the damage variable changes with stress and strain after rock yield. Under the effect of the damage threshold, the damage variable is zero if stress and strain are relatively low, then it increases gradually with undermining of rock elements and yield development of the material.

\section{Illustrative examples}

The dynamic link library (DLL) compiled using $\mathrm{C}++$ language was embedded into the finite difference software FLAC ${ }^{3 \mathrm{D}}$ for secondary development to realize programming of the constitutive model of damage. Taking the Jiangxi Road station of the Qingdao Metro, China as engineering background, a stability analysis of station excavation can be conducted by obtaining parameters of the physical and mechanical properties of the engineering rock mass from field investigation and laboratory tests. With the monitoring data from the construction process, the constitutive model can be evaluated by comparing the results of calculations in two cases, one which considers the damage effect and one which does not.
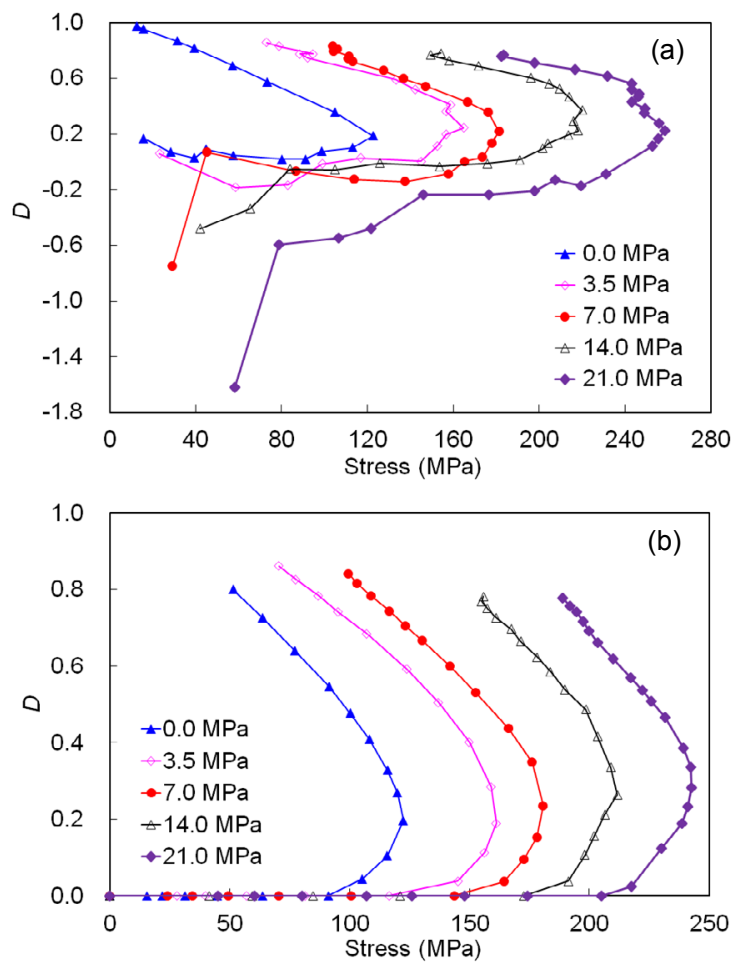

Fig. 7 Curves of damage variable changing with $\sigma_{1}$ under different confining pressures: (a) test curves of Kawamoto et al. (1988); (b) theoretical curves given in this study
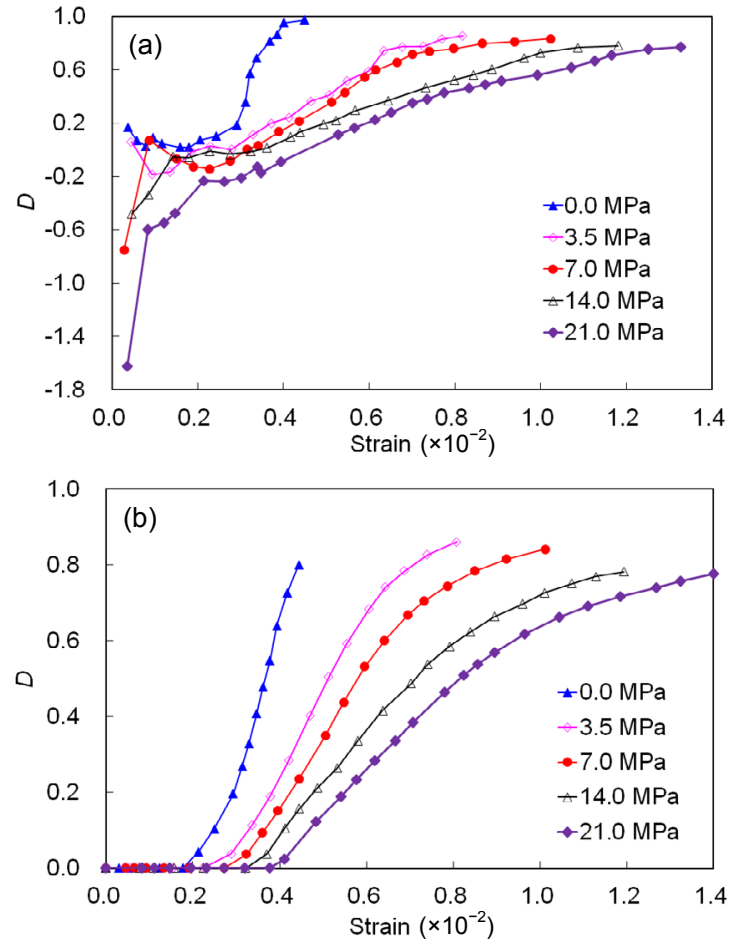

Fig. 8 Curves showing the change in the damage variable with $\varepsilon_{1}$ under different confining pressures: (a) test curves of Kawamoto et al. (1988); (b) theoretical curves given in this study 


\subsection{Project profile}

The Jiangxi Road station of the Qingdao Metro Line 3, a two-layer island platform station with a single arch, located at the junction of Nanjing Road and Jiangxi Road, was constructed by the doubleside-drift method. The overall length of the main station is $247.0 \mathrm{~m}$. The excavation section of the station is $15.5 \mathrm{~m}$ high and about $21.5 \mathrm{~m}$ wide, with the overlying depth around $10.0 \mathrm{~m}$.

The landform configuration of the station site is the piedmont slopes of erosion and accumulation, and the overlying stratum includes mainly quaternary and fully or strongly weathered granite, the strongly weathered granite being thicker. The station site has foundations with a soft upper layer and a rigid lower layer typical of the Qingdao area.

\subsection{Calculation model}

A key construction section of the project was taken to set up a numerical calculation model which could simulate excavation of the station (Fig. 9). Considering the effect of excavation disturbance, the surrounding rock on both sides of the tunnel should be 2.5 times the width of the station, and the rock

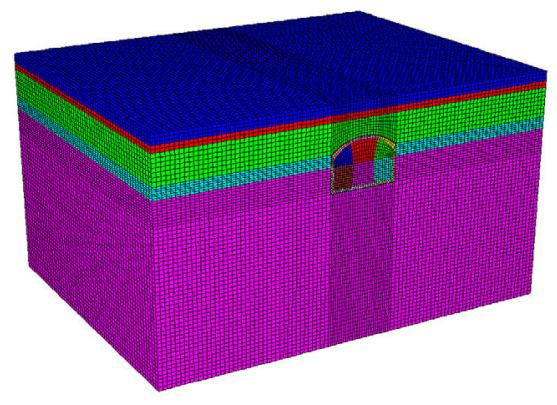

Fig. 9 Calculation model of the Jiangxi Road station of the Qingdao Metro mass on the bottom should be 3 times the station height. Therefore, the size of the $3 \mathrm{D}$ model established eventually was $129 \mathrm{~m} \times 100 \mathrm{~m} \times 72 \mathrm{~m}$, with a total of 456480 units and 474885 nodes. As for the boundary conditions of the model, the upper boundary was designed as a free surface. Horizontal and vertical constraints were considered all around and at the bottom, respectively.

The formation conditions can be simplified to five layers according to the report of geological exploration at the station site. From top to bottom, the five layers are miscellaneous fill, cohesive soil, strongly weathered granite, moderately weathered granite, and slightly weathered granite. The physical and mechanical parameters of each layer are shown in Table 1.

An elastic-perfectly plastic constitutive model was adopted for the upper soil, while the MohrCoulomb model was adopted for the yield criterion. There were two situations in relation to the lower weathered granite strata: an elastic-perfectly plastic constitutive model was adopted without considering the damage effect of rock, otherwise the constitutive model of damage was adopted. Elastic constitutive models were employed for primary support and secondary linings.

\subsection{Analysis of computing results}

\subsubsection{Distribution of the plastic zone}

After completion of the calculation, the distribution of plastic zones of surrounding rock in two cases could be extracted (Fig. 10). One case considered the damage effect and the other did not. After the excavation, the plastic zone area considering the damage effect was twice the size of that without considering the damage effect, which indicates that

Table 1 Physical and mechanical parameters of rock masses

\begin{tabular}{|c|c|c|c|c|c|c|c|c|}
\hline Layer & $\begin{array}{c}\text { Elasticity } \\
\text { modulus } \\
(\mathrm{GPa})\end{array}$ & $\begin{array}{l}\text { Poisson's } \\
\text { ratio }\end{array}$ & $\begin{array}{l}\text { Density } \\
\left(\mathrm{kg} / \mathrm{m}^{3}\right)\end{array}$ & $\begin{array}{c}\text { Yield } \\
\text { friction } \\
\text { angle }\left(^{\circ}\right)\end{array}$ & $\begin{array}{c}\text { Yield } \\
\text { cohesion } \\
(\mathrm{kPa})\end{array}$ & $\begin{array}{c}\text { Damage } \\
\text { friction } \\
\text { angle }\left(^{\circ}\right)\end{array}$ & $\begin{array}{c}\text { Damage } \\
\text { cohesion } \\
(\mathrm{kPa})\end{array}$ & $\begin{array}{c}\text { Tensile } \\
\text { strength } \\
(\mathrm{kPa}) \\
\end{array}$ \\
\hline Miscellaneous fill & 0.01 & 0.40 & 1750 & 15.0 & 10 & 16.5 & 12 & 10 \\
\hline Cohesive soil & 0.03 & 0.35 & 1900 & 22.2 & 15 & 24.3 & 20 & 45 \\
\hline $\begin{array}{l}\text { Strongly weathered } \\
\text { granite }\end{array}$ & 0.10 & 0.28 & 2300 & 31.5 & 100 & 35.0 & 120 & 65 \\
\hline $\begin{array}{l}\text { Moderately weathered } \\
\text { granite }\end{array}$ & 4.20 & 0.25 & 2450 & 35.7 & 600 & 38.5 & 680 & 220 \\
\hline Slightly weathered granite & 20.0 & 0.22 & 2500 & 40.3 & 1200 & 44.0 & 1400 & 800 \\
\hline
\end{tabular}


(a)

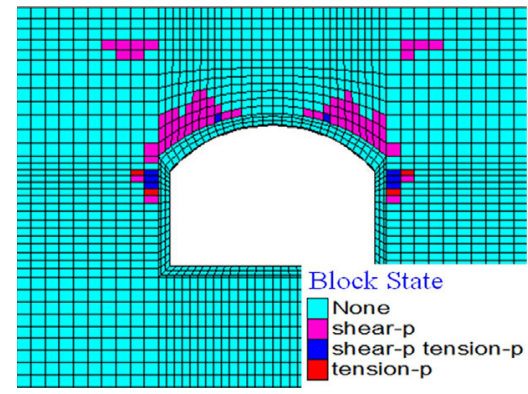

(b)

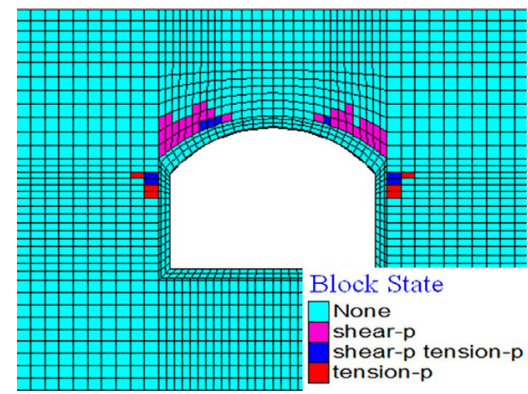

Fig. 10 Distribution of plastic zones after excavation considering (a) and not considering (b) the damage effect

the computing results are greatly influenced by the use of the damage constitutive model to correct rock parameters.

\subsubsection{Settlement deformation}

The settlement deformation of the subway tunnel is an important basis on which to judge the stability of the surrounding rock in the construction process. In combination with field monitoring data, a comparative analysis of the settlements at the crown and surface was conducted under two cases. One case considered the damage effect and the other did not (Fig. 11).

Settlements of the crown and the surface by considering the damage effect of surrounding rock were larger than those without considering the damage effect. With the progress of construction, gaps between settlement curves became wider. The largest increases in settlement were $42.90 \%$ at the crown (Fig. 11a) and $47.11 \%$ (Fig. 11b) at the surface.

In consideration of the rock damage effect, the constitutive model of damage can reflect the rock's mechanical deformation properties. Moreover, the calculated settlement deformation curves match the field monitoring data very well, which indicates that the constitutive model can reflect the deterioration effect of a soft rock mass at the site, and the computation results are reasonable and reliable.
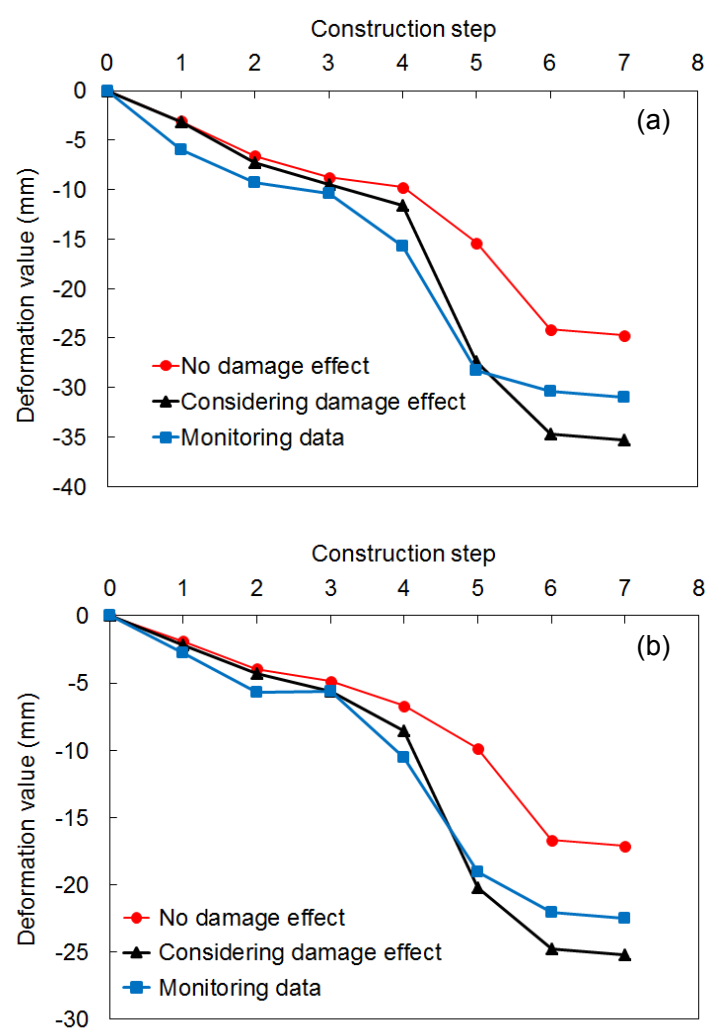

Fig. 11 A comparative analysis of the settlements at the crown (a) and the surface (b) in two cases: one considers the damage effect and the other does not

\section{Conclusions}

Based on the Mohr-Coulomb criterion, this paper deduces a statistical constitutive model of rock damage by considering the load-bearing capacity of damaged elements. The established model has already been applied in engineering practice. The main results were as follows:

1. With regard to the shortcomings of traditional damage theory, reasons for the existence of a rock damage threshold were found as a result of further analysis of the rock damage mechanism. We conclude that damaged elements can still bear stress.

2. Damage can be defined as the result of lower stiffness due to a change in the physical properties of undamaged elements. A correction coefficient of damage is introduced to correct the stress borne by damaged elements. A damage model of rock under 
different conditions is established based on the stress distribution relationship between damaged and undamaged elements.

3. The stress concentration near initial defects is the main cause of rock deterioration, along with material damage. The initial damage variable is small and difficult to calculate. Rock of different initial conditions can be regarded as materials with different properties, and the initial damage variable can be assumed to be zero, then the problem of the solution of undamaged conditions can be avoided and the damage model can be simplified reasonably.

4. A statistical constitutive model of rock damage, whose reasonability has been discussed and analyzed, was established on the basis of a triaxial compression test and the use of theories of continuum damage and statistical mechanics. The model and test curves have high fitting precision, which can reflect the stress-strain relationship of the whole process of rock failure. In particular, the description of the rock strain softening stage is more reasonable.

5. Taking the Jiangxi Road station of the Qingdao Metro Line 3 as engineering background, a stability analysis of station excavation was conducted using the established constitutive model of damage. The computation results indicate that the model can reflect the deterioration effect of the soft rock mass at the site and that the results from the model coincide well with field monitoring deformation curves.

\section{References}

Andrä, H., Combaret, N., Dvorkin, J., et al., 2013. Digital rock physics benchmarks-part I: imaging and segmentation. Computers \& Geosciences, 50:25-32. [doi:10.1016/ j.cageo.2012.09.005]

Cao, W.G., Li, X., Zhao, H., 2007. Damage constitutive model for strain-softening rock based on normal distribution and its parameter determination. Journal of Central South University of Technology, 14(5):719-724. [doi:10. 1007/s11771-007-0137-6]

Cao, W.G., Zhao, H., Zhang, L., et al., 2008. Damage statistical softening constitutive model for rock considering effect of damage threshold and its parameters determination method. Chinese Journal of Rock Mechanics and Engineering, 27(6):1148-1154 (in Chinese).

Chandler, N.A., 2013. Quantifying long-term strength and rock damage properties from plots of shear strain versus volume strain. International Journal of Rock Mechanics and Mining Sciences, 59:105-110. [doi:10.1016/j.ijrmms. 2012.12.006]

Chen, W.Q., 2014. The renaissance of continuum mechanics. Journal of Zhejiang University-SCIENCE A (Applied
Physics \& Engineering), 15(4):231-240. [doi:10.1631/ jzus.A1400079]

Deng, J., Gu, D., 2011. On a statistical damage constitutive model for rock materials. Computers \& Geosciences, 37(2):122-128. [doi:10.1016/j.cageo.2010.05.018]

Fu, Q., Xie, Y.J., Long, G.C., et al., 2013. Study on statistical damage model of triaxial creep of concrete. Engineering Mechanics, 30(10):205-210 (in Chinese).

Jiang, W., Deng, J., Li, Y., 2010. Study on constitutive model of rock damage based on lognormal distribution. Chinese Journal of Underground Space and Engineering, 6(6):1190-1194 (in Chinese).

Kaiser, P.K., Morgenstern, N.R., 1981. Phenomenological model for rock with time-dependent strength. International Journal of Rock Mechanics and Mining Sciences \& Geomechanics Abstracts, 18(2):153-165. [doi:10. 1016/0148-9062(81)90740-3]

Kawamoto, T., Ichikawa, Y., Kyoya, T., 1988. Deformation and fracturing behaviour of discontinuous rock mass and damage mechanics theory. International Journal for Numerical and Analytical Methods in Geomechanics, 12(1):1-30. [doi:10.1002/nag.1610120102]

Krajcinovic, D., Silva, M.A.G., 1982. Statistical aspects of the continuous damage theory. International Journal of Solids and Structures, 18(7):551-562. [doi:10.1016/ 0020-7683(82)90039-7]

Ladani, L.J., Dasgupta, A., 2009. A meso-scale damage evolution model for cyclic fatigue of viscoplastic materials. International Journal of Fatigue, 31(4):703-711. [doi:10. 1016/j.jifatigue.2008.03.013]

Lee, H.K., Simunovic, S., 2001. A damage constitutive model of progressive debonding in aligned discontinuous fiber composites. International Journal of Solids and Structures, 38(5):875-895. [doi:10.1016/S0020-7683(00) 00060-3]

Lemaitre, J., 1984. How to use damage mechanics. Nuclear Engineering and Design, 80(2):233-245. [doi:10.1016/ 0029-5493(84)90169-9]

Levasseur, S., Collin, F., Charlier, R., et al., 2013. A micromacro approach of permeability evolution in rocks excavation damaged zones. Computers and Geotechnics, 49:245-252. [doi:10.1016/j.compgeo.2012.12.001]

Li, S.C., Xu, J., Li, K.G., et al., 2007. Study on damages constitutive model of rocks based on Weibull distributing. Journal of Hunan University of Science \& Technology, 22(4):65-68 (in Chinese).

Li, X., Cao, W.G., Su, Y.H., 2012. A statistical damage constitutive model for softening behavior of rocks. Engineering Geology, 143-144:1-17. [doi:10.1016/j.enggeo. 2012.05.005]

Mazars, J., Cabot, G.P., 1989. Continuum damage theoryapplication to concrete. Journal of Engineering Mechanics, 115(2):345-365. [doi:10.1061/(ASCE)0733-9399 (1989)115:2(345)]

Molladavoodi, H., Mortazavi, A., 2011. A damage-based numerical analysis of brittle rocks failure mechanism. Finite Elements in Analysis and Design, 47(9):991-1003. 
[doi:10.1016/j.finel.2011.03.015]

Mortazavi, A., Molladavoodi, H., 2012. A numerical investigation of brittle rock damage model in deep underground openings. Engineering Fracture Mechanics, 90:101-120. [doi:10.1016/j.engfracmech.2012.04.024]

Rinaldi, A., Lai, Y.C., 2007. Statistical damage theory of 2D lattices: energetics and physical foundations of damage parameter. International Journal of Plasticity, 23(10-11): 1796-1825. [doi:10.1016/j.ijplas.2007.03.005]

Shan, Z.G., Di, S.J., 2013. Loading-unloading test analysis of anisotropic columnar jointed basalts. Journal of Zhejiang University-SCIENCE A (Applied Physics \& Engineering), 14(8):603-614. [doi:10.1631/jzus.A1200261]

Shi, C., Jiang, X.X., Zhu, Z.D., et al., 2011. Study of rock damage constitutive model and discussion of its parameters based on Hoek-Brown criterion. Chinese Journal of Rock Mechanics and Engineering, 30(S1):2647-2652 (in Chinese).

Wang, T.T., Wang, C., Zhang, J.B., et al., 2013. The study of rock body damage constitutive model on refracturing. Advances in Petroleum Exploration and Development, 6(2):38-40. [doi:10.3968/j.aped.1925543820130602.1786]

Wang, Z.L., Li, Y.C., Wang, J.G., 2007. A damage-softening statistical constitutive model considering rock residual strength. Computers \& Geosciences, 33(1):1-9. [doi:10. 1016/j.cageo.2006.02.011].

Xu, Q., Chen, J.Y., Li, J., et al., 2013. Coupled elastoplasticity damage constitutive models for concrete. Journal of Zhejiang University-SCIENCE A (Applied Physics \& Engineering), 14(4):256-267. [doi:10.1631/ jzus.A1200196]

Yu, S.W., Feng, X.Q., 1997. Damage Mechanics. Tsinghua University Press, Beijing, China, p.5-25 (in Chinese).

Zhang, M., Wang, F., Yang, Q., 2013. Statistical damage constitutive model for rocks based on triaxial compression tests. Chinese Journal of Geotechnical Engineering, 35(11):1965-1971 (in Chinese).

\section{中文概要}

题 目: 考虑受损基元承载影响的岩石统计损伤本构模 型及工程应用

目 的：建立三轴压缩作用下考虑受损基元承载影响的 岩石材料损伤本构关系, 并将其应用于工程实 际。

创新点: 1. 进行岩石损伤机理分析, 探讨损伤阈值存在 的原因, 提出损伤修正系数, 确定受损基元与 无损基元的应力分配关系; 2. 建立能够反映岩 石破裂全过程的损伤本构模型, 验证模型的合 理性并实现其程序化。

方 法: 1. 通过数值计算探讨岩石在初始缺陷下的损伤 劣化机理, 将不同初始状态的岩石定义为不同 岩性的无损材料, 建立合理的损伤模型；2. 基 于 Mohr-Coulomb 准则, 结合连续损伤和统计理 论, 推导基于受损基元承载影响的岩石材料本 构方程; 3 . 与前人试验数据及理论成果进行对 比, 验证本构模型的合理性, 最后利用 $\mathrm{C}++$ 语 言编译的动态链接库 (DLL) 实现有限差分软 件 FLAC ${ }^{3 \mathrm{D}}$ 的二次开发, 实现模型的工程应用。

结 论: 1. 岩体损伤劣化是无损基元发生物理性状改变 导致材料刚度变小的结果，受损基元与无损基 元的应力分配关系与岩体的瞬时损伤状态和应 力状态有关; 2. 建立的岩石损伤本构模型与试 验数据的拟合精度较高, 能够准确地描述岩石 的应力-应变关系; 3 . 数值模拟结果与现场监测 数据的吻合程度较高, 表明该模型能够合理反 映软弱岩体的损伤劣化效应。

关键词: 岩石材料; 损伤基元; 统计理论; 承载能力; 本构模型 